\title{
À PROCURA DE UM NOVO DESTINO: IMIGRANTES PORTUGUESES NO PARANÁ DA SEGUNDA METADE DO SÉCULO XIX ${ }^{1}$
}

\author{
In search of a new home: Portuguese immigrants in \\ Paraná in the second half of the nineteenth century
}

Roseli Boschilia*

\begin{abstract}
RESUMO
A dispersão geográfica, característica marcante entre os e/imigrantes portugueses, tem sido tratada, mais recentemente, como um fenômeno típico das diásporas modernas. Mais estudado do ponto de vista dos movimentos transnacionais, este fenômeno inclui também os deslocamentos migratórios internos, realizados pelos imigrantes após a chegada nas sociedades de acolhimento. A opção dos imigrantes por um novo destino teve desdobramentos não só no que diz respeito a sua experiência individual, como também contribuiu para a invisibilidade do grupo na historiografia, tendo em vista as dificuldades encontradas pelos pesquisadores para acompanhar a sua movimentação a partir da documentação existente. Com base nestas reflexões, este artigo analisa o perfil dos imigrantes portugueses que se dirigiram ao Paraná, na segunda metade do século XIX, após terem se instalado, inicialmente, em outras cidades brasileiras. Para tanto, foram elencados dois conjuntos documentais: de um lado, aqueles produzidos após a sua chegada no território paranaense (registros de desembarque, pedidos de naturalização, anúncios e documentos diversos da Sociedade Beneficente Portuguesa Primeiro de Dezembro) e, de outro, os pedidos de passaporte solicitados por esses imigrantes em distritos da região norte de Portugal.
\end{abstract}

Palavras-chave: e/imigração portuguesa; deslocamentos migratórios internos; Paraná.

* Universidade Federal do Paraná.

1 Este artigo é resultado da pesquisa de pós-doutorado, desenvolvida no Centro de Estudos de População, Economia e Sociedade (CEPESE) ligado à Universidade do Porto, sob a supervisão do Prof. Dr. Fernando de Sousa. Além de contar com o apoio financeiro da Fundação Araucária (Edital 11/2010), o trabalho de levantamento de fontes que deu origem a esta pesquisa teve a colaboração de quatro bolsistas CNPq/PIBIC (Celina Fiamoncini, Giseli Cristina dos Passos, Milena Woitovicz Cardoso e Luana Genaro), vinculadas ao projeto "Imigração e identidade: portugueses em Curitiba (séculos XIX e XX)". 


\begin{abstract}
The geographical dispersion, an outstanding characteristic of the Portuguese e/immigrants, has been, more recently, treated as a typical phenomenon of modern diasporas. Studied more from a perspective of transnational movement, this phenomenon also includes the internal migration after arriving at the receiving countries. The option of a new destination affected not only their individual experience, but has also contributed to the invisibility of the group in historiography due to the difficulties encountered by researchers in following their steps from existing sources. Based on these considerations, this article analyses the profile of the Portuguese immigrants that went to Paraná in the second half of the nineteenth century after having established themselves, initially, in other Brazilian cities. Two documentary sets have been selected for the task in hand: on the one side, those produced after their arrival in Paraná (disembarkation registers, naturalization requests, commercial advertisements and several other documents from the Sociedade Beneficente Portuguesa Primeiro de Dezembro) and, on the other side, the requests for passports made by these emmigrants from districts of the northern region of Portugal.
\end{abstract}

Key-words: Portuguese e/immigration; internal migrations; Paraná.

\title{
Introdução
}

Em julho de 1899, o imigrante português Francisco Fernandes caminhou durante aproximadamente cinco dias para atravessar a Serra do Mar e chegar a Curitiba. Nascido na região de Trás-os-Montes, na localidade de Lobão da Beira, concelho de Tondela, um ano antes ele havia solicitado passaporte com destino ao Rio de Janeiro. Ao prestar informações para a obtenção do documento, junto ao distrito de Viseu, declarou que, aos 36 anos, era solteiro, filho de Manuel Fernandes e Luisa de Loureiro e trabalhava como "jornaleiro".

Longe de se imaginar como um peão na política dos países implicados no seu destino, Francisco, como destaca Pereira (2002), do mesmo modo que outras milhares de pessoas que emigraram do norte de Portugal em direção ao Brasil, atravessou o Atlântico na esperança de encontrar sua "árvore das patacas". 
Mais do que um desejo, a migração era uma das poucas opções que restava a uma parcela empobrecida da população portuguesa, que procurava, a todo custo, fugir do desemprego, motivado pelo descompasso entre o crescimento demográfico e o modelo de desenvolvimento econômico que não permitia a absorção da mão de obra disponível.

Vale lembrar que, durante a segunda metade do século XIX, o fenômeno de deslocamento transnacional se intensificou não só em Portugal, mas em vários outros países europeus, afetados pela depressão econômica que atingiu aquele continente entre as décadas de 1870 e 1890 . Hobsbawm (1996) apoia-se em cálculos estimativos para afirmar que, somente na década de 1880 , emigraram anualmente 700 a 800 mil europeus e que, na década seguinte, esse montante teria sofrido uma elevação para algo em torno de 1 a 1,4 milhão de pessoas por ano. De acordo com Arruda (2007, p. 29), cerca de 40 milhões de europeus deixaram o continente, na condição de emigrantes, entre 1850 e 1920.

Em Portugal, apesar do clima de prosperidade que teve lugar a partir da segunda metade do século XIX, com o desaparecimento das crises cíclicas de carestia, comuns durante o antigo regime, a condição de vida dos camponeses, segundo Pereira, pouco mudou do ponto de vista econômico. A autora lembra que "a liberdade de vedar os campos, finalmente estabelecida em 1852, viria desfavorecer ainda mais os pequenos agricultores, proprietários, foreiros ou rendeiros, encorajando um processo de individualização da propriedade já em curso" (PEREIRA, 2002, p. 21).

Ao mesmo tempo, o crescente processo de urbanização das cidades brasileiras, associado ao crescimento econômico e ao avanço dos meios de comunicação, motivava o deslocamento desse numeroso e diversificado contingente populacional, do qual Francisco fazia parte.

Ao chegar ao Brasil, embora tenha declarado como destino o Rio de Janeiro, poucos meses após sua chegada, Francisco passou a residir no litoral paranaense. A motivação para o seu deslocamento para o Paraná, situado a quase $1.000 \mathrm{~km}$ da sede do império, deveu-se, provavelmente, à oferta de trabalho na Estrada de Ferro Curitiba-Paranaguá. Essa ferrovia, fruto de um arrojado projeto de engenharia, ligando a capital curitibana ao núcleo urbano mais antigo do Estado, absorveu significativo contingente de mão de obra imigrante, desde o início de sua construção, em 1880, e mesmo após ter sido inaugurada, em 1885. 
Vale notar que o interesse pela mão de obra imigrante para a construção de estradas estava na pauta do governo paranaense desde a emancipação da província, ocorrida em 1853. Em 1858, o presidente Francisco Liberato de Mattos, ao abordar a questão da carência de mão de obra para a construção de estradas da província do Paraná, noticiou a celebração de um contrato com o governo imperial, que, visando atrair "avultado número de colonos", autorizou "os negociantes Forruja Leite e Mendes do Rio de Janeiro a engajarem 50 colonos portugueses como simples operários na Estrada da Graciosa ou em qualquer serviço". 2

Alguns anos após, em 1872, ao prestar informações sobre a situação dos portugueses no Brasil, o Secretário da Caixa de Socorro D. Pedro V também destacava a importância desse trabalho para os recém-chegados:

Os trabalhos de construção de estradas de ferro offerecem hoje e continuarão a offerecer no futuro emprego a todos os braços, e o salário que as respectivas emprezas pagam é realmente tentador para os immigrantes de um paíz onde o salário é pequeno (PEREIRA, 2002, p. 268).

Mas, se do ponto de vista salarial o emprego nas ferrovias era compensador, não se podia dizer o mesmo quando se tratava das condições de trabalho às quais os imigrantes eram submetidos. No caso da estrada do litoral paranaense, além do isolamento geográfico e da constante exposição às enfermidades típicas da floresta subtropical, os trabalhadores envolvidos na construção e posterior manutenção da ferrovia também se deparavam com as precárias condições de segurança no trabalho, devido, principalmente, à acidentada topografia da Serra do Mar.

Desse modo, algum tempo depois, ao ser vitimado por um acidente na ferrovia, Francisco adoeceu, perdendo, consequentemente, sua capacidade produtiva. Desassistido pelo governo estadual paranaense, que o havia contratado para prestar serviços junto à ferrovia, a única alternativa que a ele restava para garantir a sobrevivência ou mesmo voltar a Portugal era buscar ajuda de outros imigrantes.

2 Relatório do Presidente Francisco Liberato de Mattos, apresentado na abertura da Assembleia Legislativa Provincial, em 7 de janeiro de 1858, p. 21-22. Curitiba, Tipografia Paranaense, 1858. 
Na companhia de outro compatriota, seguiu a pé até Curitiba, capital da província, situada a 15 léguas de Paranaguá, em busca do auxílio esperado. Lá chegando, após ter feito contato com portugueses ali estabelecidos, foi encaminhado à sede da Sociedade Beneficente Portuguesa Primeiro de Dezembro. Seu apelo foi ouvido, pois na sessão de 30 de julho a diretoria daquela sociedade deixou registrado em ata que aprovara a concessão de um auxílio, no valor de 300 mil réis, para que ele pudesse retirar-se para Portugal.

Por tratar-se de uma instituição sem recursos suficientes para oferecer o montante que Francisco necessitava para pagar o total da viagem até o destino final, a diretoria forneceu-lhe, juntamente com a referida quantia em dinheiro, duas cartas de apresentação: a primeira endereçada à Diretoria da Sociedade de Santos e a segunda à Associação de Socorros Mútuos, no Rio de Janeiro, com o seguinte teor:

\footnotetext{
Curitiba, $1^{\circ}$ de agosto de 1899 .

É portador do presente nosso compatriota Francisco Fernandes que, devido a um acidente que lhe houve em trabalhos da Estrada de Ferro, vê-se impossibilitado de angariar meios de subsistência devido seu precário estado de saúde, e como deseja regressar à Pátria e a nossa Sociedade está parca em recursos só nos permitindo pagar a passagem até essa; contamos que essa insígnia sociedade lhe proporcione o recurso de que é merecedor, pelo que, de ante mão, essa diretoria vos agradece (Livro de Atas da SBPPD, 1899, n. p.).
}

Depois desse registro, não foi mais possível acompanhar os rastros de Francisco para saber se ele efetivamente retornou a Portugal ou se permaneceu no Brasil. No entanto, sua história exemplifica a de tantos outros imigrantes que, frente às dificuldades de sobrevivência ou problemas de saúde, procuravam retornar ao continente europeu poucos meses depois de terem chegado ao nosso país.

Prova disso é que, desde meados da década de 1860, a Caixa de Socorros de D. Pedro V procurava acudir imigrantes que necessitavam de amparo, conforme foi apontado no relatório encaminhado por aquela entidade ao Cônsul-Geral de Portugal. 
Nos sete anos decorridos desde 1864 a 1871 a Caixa de Socorros de $\mathrm{D}$. Pedro $\mathrm{V}$ pagou a passagem para voltarem à patria a 2.304 portugueses e o numero dos que tem socorrido eleva-se a mais de 9.000 inscriptos até hoje. Estes algarismos, ex. ${ }^{\text {mo }}$ Sr. representam homens inteiramente abandonados, sem mais recurso algum e que morreriam ao desemparo se esta associação não fora (PEREIRA, 2002, p. 268).

De igual maneira, a Sociedade Portuguesa de Beneficência do Rio de Janeiro informava, em 1872, que, nos dez últimos anos, havia socorrido 18.162 emigrantes, o que totalizava $36 \%$ dos que entraram naquela cidade no mesmo período. ${ }^{3}$ Ou seja, conforme destaca Pereira (2002, p. 50), embora os dados referentes às taxas de retorno sejam dispersos e pouco precisos, estima-se que giravam entre 30 e $40 \%$ do total dos passageiros desembarcados.

É preciso considerar, no entanto, que estas taxas incluíam também imigrantes que, após retornarem a Portugal, decidiam voltar ao Brasil para fazer uma nova tentativa, dirigindo-se, normalmente, para outros lugares.

Entre os imigrantes que se radicaram no Paraná, encontramos alguns indivíduos que realizaram o percurso transatlântico mais de uma vez antes de se dirigir ao Estado. Foi o caso, por exemplo, de Antônio Augusto de Miranda, natural do distrito de Aveiro, que, ao emigrar pela primeira vez, com destino ao Rio de Janeiro, em 1883, declarou ao funcionário responsável pela emissão de passaportes que era estudante e tinha 16 anos. Cinco anos depois, retornou ao Brasil, ostentando já a profissão de negociante. Casos como estes mostram que o retorno não era um comportamento exclusivo dos que haviam fracassado, mas que as idas e vindas ao Brasil faziam parte da experiência de vida de muitos imigrantes portugueses. A historiografia acerca da imigração portuguesa também é rica em exemplos que mostram casos de indivíduos bem sucedidos - os chamados "brasileiros" ou "torna-viagem" - que, após angariar fortuna, retornavam a Portugal para investir parte do dinheiro arrecadado no Brasil (PEREIRA, 2002; ALVES, 1994; 1998; SANTOS, 2000; ROCHA-TRINDADE; CAEIRO, 2000).

3 CARVALHO, Augusto. O Brazil, colonização e emigração. Typographia de Bartholomeu H. de Moraes, 1875. p. 283-284. 
Estes, sem dúvida, deixaram diversos vestígios de suas trajetórias. Vestígios que são perceptíveis não só nos acervos documentais privados (testamentos, escrituras, fotografias, bens móveis), como ainda hoje estão presentes na memória coletiva dos habitantes de muitas cidades do norte de Portugal. Não são poucos os retornados que tiveram seus nomes vinculados a obras, monumentos e instituições públicas erigidas ou criadas graças às ações de benemerência em que estiveram envolvidos, conforme a historiografia nos mostra.

Assim, é fácil verificar que entre os e/imigrantes portugueses do século XIX não havia um único padrão de deslocamento e, portanto, longe de constituírem um grupo homogêneo, eles devem ser analisados de acordo com as suas especificidades.

Em suas análises, Alves (1994) classifica esses emigrantes em dois grupos distintos: o primeiro deles, constituído por indivíduos que dispunham de recursos para arcar com as despesas da passagem e, via de regra, podiam contar com a ajuda de conterrâneos na sociedade de acolhimento, inserindo-se com relativa facilidade nas atividades urbanas ligadas, principalmente, à área comercial. ${ }^{4}$ Já o segundo grupo era composto por emigrantes desprovidos de bens, que eram recrutados, sobretudo nos arquipélagos, para trabalhar nas fazendas rurais, em substituição à mão de obra escrava. Todavia, o autor lembra que, mesmo sem contar com o apoio das redes de solidariedade, muitos desses trabalhadores acabavam, igualmente, se dirigindo às cidades em busca de ocupações melhor remuneradas.

A ausência de formação profissional, bem como a impossibilidade de contar com as redes de apoio de imigrantes já estabelecidos, eram os fatores que mais contribuíam para o retorno dos imigrantes pertencentes a este segundo grupo, do qual Francisco, nosso personagem, fazia parte.

Diante deste panorama, em que "a fortuna teima[va] em se mostrar adversa aos emigrantes livres, que não [tinham] no Brazil parentes, amigos ou proteção" (CARVALHO, 1875, p. 283), no momento de buscar emprego nas áreas urbanas, imigrantes sem formação, que, muitas vezes, haviam embarcado graças à emissão de passaportes falsificados, ou até mesmo

4 Em um artigo onde analisa a emigração de elites do noroeste de Portugal no século XIX, Henrique Rodrigues mostra que, entre os emigrantes, havia a presença não só de negociantes, comerciantes, capitalistas, empreiteiros, industriais, armadores, ourives, relojoeiros, mas também de padres, escreventes, farmacêuticos, engenheiros, bacharéis, guarda-livros e médicos (RODRIGUES, 2007). 
na condição de viajantes clandestinos, alinhavam-se ao lado de outros que chegavam munidos de passaporte regular, carta de recomendação e comprovante de escolaridade. Neste cenário de condições tão desiguais, aos primeiros restava, normalmente, apenas a ocupação de "jornaleiro", ou seja, contratação temporária para o desenvolvimento de tarefas braçais e mal remuneradas.

A instabilidade característica desses postos de trabalho levava muitos imigrantes a se deslocarem em direção a outras áreas urbanas onde a oferta de emprego ou mesmo as condições de trabalho fossem mais atraentes. Esta foi, sem dúvida, uma das motivações para a ida de portugueses ao Paraná que, no contexto da segunda metade do século XIX, graças à expansão da economia do mate, se abria como um espaço de trabalho promissor para diferentes grupos de imigrantes europeus.

\section{A presença portuguesa no território paranaense}

Até o início da segunda metade do século XIX, o termo Paraná, de origem indígena, estava muito mais associado ao nome de um rio do que propriamente ao espaço territorial que, a partir de 1853, passou a sediar a recém-criada província do Paraná, desmembrada politicamente da província de São Paulo graças ao incremento da produção de erva-mate.

Parcamente povoada e desprovida de qualquer infraestrutura, a jovem província necessitava atrair mão de obra destinada não só à abertura de estradas, conforme já foi referido anteriormente, mas, sobretudo, à produção agrícola, voltada prioritariamente ao mercado interno.

A política implantada pelo governo nessa direção acabou atraindo diferentes grupos de imigrantes europeus, entre os quais se destacaram germânicos, poloneses e italianos, que passaram a ocupar extensas áreas agrícolas nos arredores da capital da província. ${ }^{5}$

5 Além desses três grupos, o Paraná recebeu, ainda no século XIX, significativo contingente de imigrantes ucranianos que se estabeleceram, prioritariamente, em colônias um pouco mais afastadas da capital (ANDREAZZA, 1999). 
O rápido crescimento populacional, motivado pela chegada desses novos grupos de imigrantes, especialmente a partir da década de 1870 , fez crescer a demanda por artigos de consumo ligados não só ao ramo do vestuário, dos calçados, de alimentos e medicamentos, mas também de outros produtos, como instrumentos agrícolas e utilidades domésticas. Neste contexto, antigos comerciantes portugueses que, ao lado dos alemães, detinham a hegemonia do comércio em Curitiba, tiveram necessidade de ampliar os seus negócios e promover a vinda de jovens caixeiros que pudessem auxiliá-los no atendimento ao público e até mesmo na administração das casas de comércio.

De igual maneira, as novas possibilidades de comércio oferecidas pelo rápido crescimento demográfico e a expansão econômica que se descortinava nas duas principais cidades da província também incentivaram a vinda de outro grupo de imigrantes portugueses, constituído por representantes comerciais ligados a empresas lusitanas do Rio de Janeiro e São Paulo, cujos proprietários tinham interesse em ampliar sua rede de negócios para além destes polos.

Sendo assim, nota-se que, ao contrário dos demais grupos de imigrantes europeus que nesta mesma época chegaram ao Paraná acompanhados por seus familiares e se fixaram em áreas específicas, os portugueses chegavam sós, instalando-se, aleatoriamente, no espaço urbano. Além disso, outra característica marcante no perfil deste grupo era a sua condição de reimigrante, uma vez que a maior parte deles chegou ao Paraná após ter se instalado inicialmente em outras cidades brasileiras.

A condição de reimigrante, devido a esse deslocamento interno, motivou a adoção de uma postura teórica que, para além de considerar o movimento de dispersão geográfica como um fenômeno típico das diásporas modernas, defende que o fenômeno do transnacionalismo deve levar em conta a multiplicidade de esferas nas quais os indivíduos realizam e tomam decisões, tanto na sociedade de origem como na de destino, conforme afirmam Kerbauy e Truzzi (2007, p. 132), ancorados nas reflexões de Glick-Schiller, Basch e Blac-Szanton (1992). Ou seja, nessa perspectiva, a experiência da emigração não se encerra com o fenômeno do deslocamento transnacional ou ainda com a decisão tomada pelo emigrante de permanecer na sociedade de acolhimento, sendo necessário problematizar as escolhas e as estratégias adotadas pelos imigrantes também na sociedade de destino. 
A partir deste olhar, a própria indefinição do estatuto social do e/ imigrante põe à mostra a situação de vulnerabilidade à qual ele é submetido quando toma a decisão de emigrar ou, por diferentes razões, é forçado a viver a experiência do deslocamento geográfico transnacional e, posteriormente, um novo deslocamento interno, não previsível. Nessa perspectiva, é importante lembrar, conforme nos alerta o estudioso da cultura Homi Bhabha (1998, p. 20), que a mobilidade interna na sociedade de destino se configura como uma nova experiência de deslocamento, um novo processo de desterritorialização que exige que o imigrante formule estratégias no sentido de reorganizar a sua realidade social de acordo com o contexto no qual se encontra.

A opção de dirigir-se a um local diferente daquele onde haviam desembarcado inicialmente, além de acarretar problemas de cunho identitário e no âmbito cultural, ainda contribuiu para a marginalização desses imigrantes na própria historiografia. No caso paranaense, por exemplo, enquanto a presença dos demais grupos étnicos que se radicaram no Estado pode ser rastreada a partir de documentos estatais e religiosos, os imigrantes portugueses que chegaram no mesmo período, ao contrário, têm menor visibilidade na documentação produzida por estes órgãos.

É preciso destacar, entretanto, que essa invisibilidade nas fontes históricas não pode ser atribuída única e exclusivamente ao caráter autônomo ou à condição de reimigrante, o que, sem dúvida, contribuiu para o seu anonimato, mas, fundamentalmente, à dificuldade encontrada pelos pesquisadores para caracterizá-los como estrangeiros nos arquivos documentais existentes, devido às semelhanças com os nomes luso-brasileiros.

O interesse em problematizar questões vinculadas ao perfil particular deste grupo, pela aparente invisibilidade, motivou a pesquisa de diferentes modalidades de fontes que pudessem fornecer pistas sobre a presença deste grupo étnico no Estado. Inspirada pelos ensinamentos do filósofo Walter Benjamin (1987), decidimos ir em busca de fragmentos que, de algum modo, possibilitassem a reconstrução da trajetória desses imigrantes.

O primeiro passo neste sentido consistiu no levantamento da documentação existente na Sociedade Beneficente Portuguesa Primeiro de Dezembro (SBPPD). Lá foi encontrado um conjunto de documentos que retrata a trajetória da sociedade desde a sua fundação, em 1878, até os dias atuais. Além dos estatutos, o livro de registros dos associados, as atas e a coleção de correspondências da entidade nos possibilitaram conhecer a 
política interna do grupo, bem como as práticas adotadas para cumprir os objetivos preconizados no documento de criação da entidade. ${ }^{6}$

Vale notar que, diferentemente da maioria das associações portuguesas existentes no Brasil durante o século XIX, que aceitavam a presença de não imigrantes em seus quadros associativos, a de Curitiba estava voltada exclusivamente aos imigrantes portugueses. O caráter exclusivista da entidade, no período de análise, facilitou enormemente a identificação do grupo, permitindo maior grau de segurança no trabalho de pesquisa. Contudo, infelizmente, as informações disponíveis nos arquivos da SBPPD limitam-se, basicamente, a identificar o associado e mencionar o ano de ingresso ou saída da associação. Raramente encontramos informações como o lugar de origem, idade ou profissão dos associados. ${ }^{7}$

Nesta direção, numa segunda etapa e com a ajuda de alunos bolsistas, foram pesquisados os documentos produzidos pela esfera governamental, incluindo-se neste conjunto de fontes históricas não somente os Relatórios de Presidente de Província e, posteriormente do Estado, mas também as listas de passageiros desembarcados no Porto de Paranaguá, bem como os pedidos de naturalização. ${ }^{8}$ A análise desta documentação em especial mostrou que, a partir da segunda metade do século XIX, os portugueses atuavam não só no comércio das duas maiores cidades da província, mas também estavam envolvidos no processo de colonização do litoral paranaense, ao lado de outros colonos de diversas nacionalidades. ${ }^{9}$

6 BOSCHILIA, Roseli. A sociedade portuguesa em Curitiba: um projeto identitário (18781900). In: MATOS, Maria Izilda; SOUSA, Fernando de; HECKER, Alexandre. (Org.). Deslocamentos e histórias: os portugueses. Bauru: Edusc, 2008, v. 1, p. 339-355.

7 Em relação ao local de origem desses imigrantes, embora sejam poucos os associados que o declaram, encontramos associados naturais dos seguintes concelhos: Viseu, Cabeceiras de Basto, Torres Novas, Villa Real, Porto, Ponte de Lima, Villa do Conde, Marco de Canaveses, Melgaço. Com exceção de Torres Novas, que se localiza no centro de Portugal, as demais cidades são todas da região norte, local do qual partiu a grande maioria dos imigrantes que se fixaram em outras cidades do Brasil, conforme aponta a historiografia.

8 O levantamento da documentação referente aos pedidos de naturalização, realizado pela bolsista Giseli Cristina dos Passos, junto ao Arquivo Público do Paraná e à Câmara Municipal de Curitiba, resultou no trabalho monográfico intitulado Presença dos portugueses no Paraná na segunda metade do século XIX e início do XX (PASSOS, 2009).

9 Na década de 1870, o presidente da província, Adolpho Lamenha Lins, comunicava a introdução de 118 imigrantes para trabalhar em uma colônia do litoral paranaense, dentre os quais estavam colonos de várias nacionalidades, inclusive portugueses (Relatório do Presidente Adolpho Lamenha Lins, apresentado a Assembleia Legislativa do Paraná, em 15 de fevereiro de 1876, p. 90-92. Curitiba, 1876). Na década de 1880 , outros dois relatórios contêm dados a respeito do número de portugueses que transitaram pelo litoral paranaense. $\mathrm{O}^{\circ}$, de 1884 , notificou a entrada de 28 portugueses e a saída de 34 deles (Relatório do Presidente Luiz Alves L. de Oliveira, apresentado em 22 de agosto de 1884, p. 14). 
Um terceiro conjunto de fontes pesquisadas, com o intuito de aprofundar a análise sobre a presença do grupo no Estado, foi a documentação produzida pela imprensa periódica paranaense. $\mathrm{O}$ trabalho de pesquisa realizado por Fiamoncini ${ }^{10}$, a partir dos anúncios publicados em dois jornais curitibanos, mostrou que entre os comerciantes paranaenses havia um número significativo de portugueses não só na área de secos e molhados, mas também no ramo farmacêutico.

Para além das análises acerca da atuação dos portugueses na sociedade paranaense, no que diz respeito especialmente ao comportamento econômico e sociocultural adotado pelo grupo, bem como às estratégias para inserir-se na sociedade de acolhimento ${ }^{11}$, a documentação pesquisada permitiu ainda a construção de um banco de dados contendo os nomes de 425 portugueses que, durante a segunda metade do século XIX, se estabeleceram no Paraná.

No entanto, apesar dos avanços obtidos a partir das reflexões realizadas com base nesta documentação local, algumas questões ligadas, sobretudo, à origem e ao percurso realizado pelos imigrantes portugueses radicados no Paraná ainda permaneciam em aberto: qual era o perfil socioeconômico desses emigrantes quando deixaram Portugal? De onde, quando e para onde vieram? Que idade eles tinham ao emigrar? Possuíam formação escolar ou profissional? Foi na tentativa de buscar resposta para estas questões que fizemos o caminho inverso ao dos imigrantes, indo em busca dessas informações nos arquivos portugueses.

10 FIAMONCINI, Celina. Imigração, Cultura e Identidade: portugueses e o comércio em Curitiba no final do século XIX. Monografia (Bacharelado em História) - Setor de Ciências Humanas, Letras e Artes, Universidade Federal do Paraná, Curitiba, 2008.

11 Neste sentido cabe lembrar os trabalhos realizados, no âmbito da Iniciação Científica, por CARDOSO, Milena W. José Fernandes Loureiro: um imigrante português em Curitiba - 1860-1908. Curitiba: UFPR, 2010; e GENARO, Luana C. A inserção dos descendentes de imigrantes portugueses no campo intelectual de Curitiba (1912-1938). Curitiba: UFPR, 2011. 


\section{A pesquisa nos arquivos portugueses: em busca das origens}

Portando na bagagem um banco de dados, contendo os nomes dos imigrantes previamente levantados nos arquivos paranaenses ${ }^{12}$, realizamos o trabalho de cruzamento destas informações com a documentação referente aos pedidos de passaporte realizados em quatro distritos do norte de Portuga $1^{13}$, região de onde saiu a maior parte dos emigrantes que, durante a segunda metade do século XIX, se dirigiu ao Brasil.

$\mathrm{O}$ trabalho de pesquisa foi enormemente facilitado pelo fato de a documentação, que está sob a guarda dos respectivos arquivos distritais, se encontrar disponibilizada em uma base de dados produzida pelo Centro de Estudos de População, Economia e Sociedade (CEPESE), ligado à Universidade do Porto, que contém mais de 300 mil registros de emigrantes, cobrindo o período entre 1835 e 1973.

Os registros de pedido de passaporte constituem um documento ímpar para conhecer o perfil socioeconômico dos emigrantes, pois, além dos dados pessoais, como nome, local de origem, concelho, idade, estado civil, profissão e características físicas (altura, formato dos olhos, cicatrizes, bigode etc.), fornece outras informações, como local de destino, tipo de viagem (ida ou retorno), data da solicitação e número do passaporte e, por último, observações como, por exemplo, se o emigrante sabia ler e escrever, se viajava acompanhado, se ia recomendado a alguém ou se embarcaria em um porto distante do distrito onde o passaporte fora solicitado.

Com o intuito de levantar os nomes dos emigrantes portugueses com maior probabilidade de se dirigir ao território paranaense, no que se refere ao local de destino, privilegiamos os registros que mencionavam os estados brasileiros mais próximos ao Paraná ou, ainda, genericamente, apenas o nome do país. Desse modo, foram pesquisados todos os registros nos quais os emigrantes, no momento de solicitar o passaporte, declararam como destino o Brasil ou os Estados do Rio de Janeiro, São Paulo, Paraná,

12 Foram encontrados, no total, 489 nomes, porém, com a retirada dos repetidos (64), restaram 425.

13 A pesquisa contemplou a documentação existente nos arquivos distritais de Porto, Aveiro, Viseu e Bragança. À época, os atuais distritos de Braga e Viana do Castelo pertenciam ao distrito do Porto. 
Santa Catarina e Rio Grande do Sul, que, à época, pertenciam à região sul do país. Todavia, excepcionalmente, além destes registros foram levantados igualmente aqueles que faziam referência a emigrantes que, mesmo tendo mencionado como destino regiões distantes do eixo geográfico mais próximo ao Paraná, sabidamente se radicaram neste Estado. ${ }^{14}$

Com base nestes critérios foram localizados, inicialmente, 148 dos nomes relacionados na base de dados, construída a partir do levantamento realizado em arquivos paranaenses. Entretanto, o alto índice de registros cujos titulares do passaporte possuíam nomes idênticos tornou a tarefa de identificação mais complexa, o que nos levou à retirada destes nomes da tabela geral, tratando-os individualmente, em tabelas à parte. ${ }^{15} \mathrm{Na}$ tentativa de selecionar um único nome em cada tabela, foram privilegiados os registros que continham dados que mais se aproximavam das características do imigrante referido na documentação paranaense, sobretudo no que dizia respeito à idade, ao estado civil, à profissão, ao local de origem ou à década em que esses emigrantes partiram de Portugal. Assim, foram incorporados à tabela geral e computados na análise 26 dos 41 nomes de pessoas que tinham homônimos, enquanto 15 tiveram que ser descartados, devido à impossibilidade de se estabelecer um critério de seleção confiável.

Ao final deste processo, foram localizados no banco de dados do CEPESE 133 dos 425 nomes levantados, inicialmente, nos arquivos paranaenses, o que representou a identificação de $1 / 3$ dos imigrantes pesquisados. Esse percentual, além de refletir as dificuldades apontadas com relação à operacionalização da pesquisa, permite supor a existência de grande número de imigrantes clandestinos entre os portugueses que se radicaram no Paraná, sem esquecer, é claro, que uma parcela dos imigrantes não localizados na documentação pesquisada pode ter partido de outras regiões de Portugal. Nesse sentido, um aspecto a ser destacado diz respeito à população feminina. Apesar de termos localizado o nome de, pelo menos, 16 mulheres imigrantes nos arquivos paranaenses, nenhum registro sobre elas foi encontrado junto à base de dados do CEPESE. Essa ausência reforça a ideia de que, embora

14 Foram contemplados na análise seis imigrantes que declararam que pretendiam ir ao Pará e um à Bahia e cujos nomes apareciam apenas uma única vez na base de dados.

15 No total, foram encontrados na Base do CEPESE 41 indivíduos $(32,3 \%)$ que possuíam nomes idênticos aos de outros emigrantes. Ou seja, um em cada três dos emigrantes que se radicou no Paraná tinha homônimos. 
os emigrantes partissem predominantemente do norte de Portugal, nem todos eram oriundos daquela região.

O levantamento feito nos arquivos portugueses, além de evidenciar o caráter majoritariamente masculino dos imigrantes que se radicaram no Paraná, mostrou a predominância de indivíduos nascidos nos distritos do Porto (43,6\%) e Aveiro (18,1\%). Quanto ao local de destino, o Rio de Janeiro $(52,7 \%)$ era a cidade mais procurada. Na sequência, aparecem em maior número os registros onde consta apenas o nome do país como destino preferencial para $12 \%$ destes emigrantes.

No que se refere à data de chegada ao Brasil, o período com maior número de solicitações de passaporte foram as duas últimas décadas do século XIX, totalizando $77 \%$ dos registros pesquisados. Neste momento, como se sabe, o Paraná atravessava um período extremamente favorável do ponto de vista econômico graças à cultura da erva-mate, cujo processo de produção, beneficiamento e comercialização gerava demanda de mão de obra em diferentes setores, que iam da construção de estradas até a área de prestação de serviços, passando pelo incremento do comércio e da indústria. Neste cenário, os portugueses, embora fossem originários, predominantemente, da área rural, mostravam versatilidade, inserindo-se no mercado de trabalho urbano como carroceiros, barriqueiros, operários, caixeiros, marceneiros, comerciantes ou ervateiros. Essa diversidade de ocupações, para além de evidenciar o caráter heterogêneo do grupo na sociedade de acolhimento, expressava as diferenças existentes entre os imigrantes no momento anterior à emigração, no que dizia respeito ao seu perfil socioeconômico.

Com efeito, a partir das informações fornecidas pelos próprios emigrantes, no momento de requisitar o passaporte, foi possível detectar a presença de três grupos distintos entre a população portuguesa que se radicou no Paraná.

O grupo mais numeroso (45\%) era constituído de homens solteiros entre 21 e 40 anos, que, do mesmo modo que Francisco, nosso personagem, partiam sem qualquer formação ou profissão definida e, em função disso, procuravam inserir-se no mercado de trabalho como jornaleiros, criados ou simplesmente trabalhadores braçais. A saída de elevado percentual desses imigrantes, como se sabe, devia-se, em grande medida, à "diminuição duma mão de obra camponesa semiempregada, que o lento crescimento 
industrial não permitia absorver" (PEREIRA, 2002, p. 11). Nessa mesma direção, Alves (1994, p. 79) recorda que as crises econômicas que atingiram Portugal em 1854 e 1856, associadas à epidemia de cólera que, em 1855, varreu o país, foram responsáveis pela saída de grande número de emigrantes a partir de meados do século XIX. Além disso, as desarmonias do crescimento determinariam, um pouco mais tarde, a incidência de outras crises setoriais, como a da viticultura do Alto-Douro e regiões limítrofes (PEREIRA, 2002, p. 22).

Outro fator que favorecia a maior concentração de indivíduos nesta faixa etária entre os imigrantes estava vinculado à dimensão fiscalizadora e repressiva da legislação portuguesa, que dificultava a obtenção de passaportes aos menores de idade, autorizando a sua emissão apenas aos maiores de 25 anos, emancipados e que estivessem isentos das obrigações ligadas à lei de recrutamento militar (RODRIGUES, 2006, p. 27).

Vale lembrar, no entanto, que, apesar da maior facilidade para atender as formalidades legais, esses emigrantes, com frequência, se deparavam com dificuldades financeiras para levantar o dinheiro necessário para viabilizar o projeto da emigração. Além das despesas para a obtenção do passaporte e da passagem, era preciso prever outros gastos, como o deslocamento até o porto de embarque, a alimentação durante a travessia e a aquisição de roupas e de, pelo menos, um par de sapatos. Por fim, o emigrante ainda necessitava dispor de uma pequena quantia em dinheiro para garantir a sobrevivência nos primeiros dias após a chegada ao Brasil. Desse modo, o investimento necessário para concretizar o projeto girava em torno de $50 \$ 000$ réis. $^{16}$ Tendo em vista que raramente um lavrador dispunha do montante necessário para cobrir tais despesas, a decisão de emigrar implicava na participação de pessoas, conhecidas ou não, que faziam o adiantamento do dinheiro, mediante o compromisso da família em arcar com a dívida. Dependendo de quem oferecia o empréstimo, essa transação podia configurar desde um simples contrato verbal até intrincadas operações de crédito, geralmente garantidas por hipoteca de terrenos ou imóvel da família. Neste último caso, era comum a participação dos agentes de emigração, que adiantavam o empréstimo (LEITE, 2000, p. 34) cobrando, normalmente,

16 Uma viagem na proa do navio custava $28 \$ 000$ réis; se fosse na mezena (mastro) custava $43 \$ 000$ réis e na $2 .^{a}$ mezena $48 \$ 000$ (CAPELA, 1999, p. 175). 
elevadas taxas de juros. Para saldar a dívida e não correr o risco de ter os seus bens confiscados, a família dependia do envio das remessas que seriam feitas pelo imigrante após o seu estabelecimento no Brasil.

O compromisso em quitar a dívida assumida pela família exigia que esses emigrantes, apesar da falta de qualificação profissional que caracterizava a maior parte dos representantes desse grupo, buscassem uma colocação no mercado de trabalho, cuja remuneração, além de garantir a sua sobrevivência, possibilitasse o envio regular de remessas para o pagamento do empréstimo.

A outra opção para quem não podia contar com a ajuda de parentes ou conhecidos e cuja família não possuía bens a serem hipotecados era o engajamento. Ou seja, antes de partir o emigrante era contratado, por intermédio de um agente, por um engajador que, além de custear o valor da passagem, fornecia a ele uma declaração com a promessa de emprego no Brasil. Ao desembarcar, o emigrante era entregue a um empregador a quem deveria prestar serviço até que a dívida referente às despesas totais da viagem fosse paga. Foi o que aconteceu, por exemplo, com Jaime Dias Fonseca, natural do concelho de Águeda que, aos 21 anos, embarcou com destino ao Rio de Janeiro, em 1895, para desembarcar, logo depois, em Paranaguá, na companhia de outros trabalhadores que vinham trabalhar na agricultura.

$\mathrm{O}$ desejo de um emprego melhor remunerado ou a possibilidade de um negócio mais lucrativo talvez tenha motivado o deslocamento de emigrantes como António Duarte Velloso e Alfredo Correia que, na virada do século XIX, saíram do Rio de Janeiro com destino ao Paraná. Dez anos após terem deixado suas aldeias, na condição de simples lavradores, ambos já eram renomados comerciantes nas praças de Curitiba e Paranaguá, respectivamente. $\mathrm{O}$ que se depreende a partir de exemplos como estes é que muitos imigrantes, "a despeito do seu freqüente analfabetismo e da total ausência de recursos à data da chegada ao Brasil, acaba[va]m por prosperar e mesmo enriquecer" (ROCHA-TRINDADE; CAEIRO, 2000, p. 9). Porém, é preciso recordar que, como Francisco, nem todos os imigrantes tiveram a mesma sorte, pois, segundo estimativas feitas no Rio de Janeiro, de cada cem imigrantes apenas um conseguia enriquecer, dez se tornavam remediados e os restantes sobreviviam (PEREIRA, 2002, p. 46).

Com um perfil distinto, encontramos um segundo grupo de imigrantes composto de homens adultos que, ao chegar ao Paraná, já tinham 
experiência na área do comércio ou algum pecúlio. Dos 83 indivíduos identificados no banco de dados, $18 \%$ deles eram negociantes ou possuíam alguma propriedade. A faixa etária na qual estavam inseridos, embora fosse bastante elástica, concentrava-se entre os 32 e 42 anos.

De acordo com a historiografia, muitos destes emigrantes eram homens casados que sentiam a pressão das dívidas acumuladas e se preocupavam com o futuro dos filhos (LEITE, 2000, p. 32).

Uma característica comum entre os representantes deste grupo eram as viagens realizadas regularmente à Europa, antes e mesmo após terem se fixado no Paraná. António Manoel da Silva, por exemplo, veio ao Brasil quatro vezes, a partir de 1891, antes de fixar-se definitivamente em Curitiba. Quando embarcou pela quarta vez, em 1898, com destino ao Rio de Janeiro, declarou que era natural de Vouzela, tinha 42 anos, era casado e sabia ler e escrever. Dois anos depois, estava estabelecido em Curitiba, como proprietário do armazém de molhados "Ao Pharol do Sul”, na Rua Quinze de Novembro. ${ }^{17}$

Com um percurso semelhante, o negociante Antônio Ribeiro dos Santos, nascido em Gaia, também emigrou para o Brasil quatro vezes, a partir de 1879. Quando desembarcou no Rio de Janeiro, em 1894, declarou que tinha 55 anos e era solteiro. Cinco anos depois, estava radicado em Curitiba e fazia parte do quadro associativo da SBPPD.

Os registros mostram que enquanto alguns viajavam com certa regularidade, outros demoravam anos, ou até décadas, para reencontrar os familiares que haviam permanecido em Portugal, tal como ocorreu com o imigrante Bernardino Fernandes de Oliveira, que deixou Portugal, com destino ao Rio de Janeiro, em 1878. Ao funcionário responsável pelos dados do seu passaporte declarou que tinha nesta data 22 anos, era trabalhador, solteiro e natural do concelho de Vila Nova de Gaia. Embora não tenha mencionado o Paraná como destino, tinha ali, sem dúvida, boas perspectivas de trabalho, pois seus primos, Manoel e José Fernandes Loureiro, eram prósperos comerciantes na capital do Estado. Somente quinze anos após, em 1893, encontramos novas informações a seu respeito, quando os referidos comerciantes tomam a decisão de noticiar, em um jornal curitibano, a morte de "seo bom e presado amigo e primo Bernardino Fernandes de Oliveira",

17 BOLETIM INFORMATIVO DA CASA ROMÁRIO MARTINS. Rua XV e o comércio no início do século. Curitiba, v. 23, n. 113, p. 19, nov. 1996. 
ocorrida, em Lisboa, "e convidam seos amigos para assistirem missa por sua alma" (Jornal A República, abril de 1893).

Já o caso do imigrante Manoel Maria Nunes Alves, nascido em 1861 no concelho de Albergaria a Velha, também é bastante peculiar. Embora estivesse radicado em Curitiba desde 1886, onde mantinha um comércio de "fazendas, modas, armarinhos", em sociedade com outros dois compatriotas (Jornal Dezenove de Dezembro, fevereiro, 1886) somente em 1893 encontramos o primeiro registro de sua saída de Portugal. Nessa data, declarou que tinha 32 anos, era solteiro, proprietário e seguia com destino ao Rio de Janeiro. Interessante notar que a referida viagem ocorreu exatamente um ano após o imigrante ter comunicado, por meio de um anúncio de jornal, que iria se ausentar, temporariamente, devido a uma viagem à Europa (Jornal A República, abril, 1892). Embora seja difícil conhecer o motivo pelo qual não existem referências nos registros de passaporte a respeito da primeira viagem ao Brasil, várias hipóteses podem ser levantadas: ele teria embarcado ainda criança, como acompanhante de outra pessoa que era o titular do passaporte; teria embarcado em outro porto; teria embarcado clandestinamente ou teria viajado como turista e não como imigrante. Com relação a essa última hipótese, vale lembrar que, além da carência de informações sobre os deslocamentos realizados internamente pelos imigrantes, após o desembarque, um aspecto que trouxe complexidade à pesquisa está relacionado ao tratamento diferenciado que era concedido aos emigrantes, dependendo da classe em que viajavam. Tendo em vista que apenas os passageiros de $3^{\mathrm{a}}$ classe eram considerados emigrantes, enquanto os de primeira e de segunda classe eram tratados como turistas, os e/imigrantes que tinham condições de pagar uma passagem de valor mais caro podiam seguir livremente para o destino que entendessem, sem qualquer controle por parte da fiscalização marítima (ROCHA-TRINDADE; CAEIRO, 2000, p. 27).

Já o terceiro e último grupo de imigrantes que veio para o Paraná, na segunda metade do século XIX, era constituído por rapazes jovens, cuja idade variava entre 10 e 16 anos. Foram encontrados, no total, 13 registros de indivíduos pertencentes a essa faixa etária. Ou seja, pertenciam a esse grupo $15 \%$ dos imigrantes ${ }^{18} \mathrm{e}$ aproximadamente a metade deste percentual

18 Esse percentual poderia ser um pouco maior se fossem computados cinco emigrantes, entre 12 e 18 anos, que, embora não tenham declarado a ocupação, informaram saber ler e escrever. 
chegou ao Brasil antes dos 14 anos. Esse foi o caso, por exemplo, de José Pereira Linhares, que residiu no município da Lapa e do negociante Antonio Henrique Gomes, natural de Oliveira de Azeméis, que se estabeleceu em Paranaguá. Ambos saíram de Portugal quando tinham, respectivamente, 11 e 12 anos.

Como se sabe, o governo português procurava impedir o embarque de maiores de 14 anos, exigindo o pagamento de fiança ou hipoteca de bens para custear despesas decorrentes do serviço militar. Todavia, as novas portarias publicadas no final da década de 1850 acabaram "por incentivar a fuga de crianças e jovens dos 10 aos 13 anos, antecipando a idade de saída para o Brasil" (RODRIGUES, 2006, p. 27).

Nesse contexto, muitos imigrantes adultos vinham para o Brasil trazendo filhos menores e, quando não podiam fazê-lo, procuravam encaminhá-los sob os cuidados de um tio, de um irmão, primos ou até mesmo amigos e vizinhos (ALVES, 1994, p. 78).

Graças às observações feitas pelo funcionário no momento da emissão do passaporte, é possível saber que, em 1885, Manuel Gomes de Barros, nascido em Póvoa de Varzim, viajou, aos 10 anos, na companhia de seu pai, com destino a Porto Alegre, ou ainda, que David de Almeida, nascido em Vouzela, na região de Trás-os-Montes, desembarcou em Paranaguá, em 1886, aos 11 anos, na companhia de seu pai, o agricultor João Marques Francisco.

Porém, a partir da idade de 15 anos, era mais comum que esses menores viajassem desacompanhados e declarassem ter uma profissão. Em 1896, António Rodrigues da Costa, de modo semelhante a outros jovens de sua idade, embarcou na cidade do Porto com destino a São Paulo. Ao funcionário do concelho de Carregal do Sal, onde residia, declarou que tinha 15 anos, era caixeiro, sabia ler e escrever e viajava "recomendado a José Lopes Leitão".

Já António José Guimarães, natural de Arouca e um ano mais velho do que o caixeiro acima referido, ao embarcar para o Rio de Janeiro, em 1880 , declarou ter a profissão de torneiro. O perfil desses dois jovens, com formação escolar e profissional, mostra que a decisão de emigrar, longe de ser individual, tomada de modo fortuito, apenas na tentativa de fugir da miséria ou de realizar o sonho da fortuna, era na verdade um projeto familiar, que envolvia investimento econômico e planejamento a longo prazo. 
Desde o século XVII, conforme lembra ALVES (1994, p. 67-69), a migração juvenil foi um fenômeno constante, sobretudo nas zonas de minifúndio, como era o caso do noroeste português, onde as unidades familiares contavam com excedente de mão de obra. Dirigidas não só para os núcleos urbanos como Porto e Lisboa, mas também para a região do Alentejo, para Castela e para o Brasil, essas migrações eram, segundo o autor, um fator de equilíbrio da economia doméstica.

A decisão das famílias dessa região de investir na formação dos filhos antes de encaminhá-los ao Brasil é evidenciada em testamentos e inventários, nos quais os pais deixaram registros acerca dos gastos realizados para promover a emigração dos filhos. Como exemplo disso, no ano de 1865, Antonio Santos Vilar declarou em testamento que teve "um gasto enorme" com dois de seus cinco filhos, que foram para o Brasil. Além das despesas de viagem e mais arranjos, também mencionou ter gasto $10 \$ 000$ rs para livrar um deles do recrutamento militar (ALVES, 1994, p. 76).

Conforme a historiografia mostra, o investimento feito por essas famílias para promover a emigração dos filhos era uma das estratégias que visavam assegurar a integridade do patrimônio familiar (ALVES, 1994). Sendo assim, uma das medidas utilizadas pelas famílias rurais para evitar a divisão da propriedade era a de favorecer um único herdeiro, que deveria permanecer na unidade familiar e proteger os pais na velhice, procurando assegurar aos demais a parte correspondente de seu quinhão (chamado de "legítima"), em moeda.

De acordo com ALVES (1994, p. 89), o destino emigratório pode ser considerado uma imposição da família, cujo comportamento estava radicado no habitus e no sentido prático da população local. Essa imposição, bem como o necessário registro das despesas realizadas, é perceptível no teor de documentos, conforme pode ser visto abaixo:

O meu filho José Joaquim de Lima Junior no estado delle solteiro o impuz para o Brasil para ganhar a sua vida, e gastei com ele o que contará do mesmo inventário. E mais uma segunda vez foi outra vez para o Brasil depois delle estar casado e também gastei com elle muito a nossa custa cuja despeza constará do inventário e como essas duas passagens e gastos que fiz com elle excede muito a sua legítima materna que lhe pertence e por isso por esta forma ficou elle pago della ficando elle para 
conferir o inventário paterno o qto excedeo aquelle (Livro de registro de testamento n. 3195, p. 14-17, de José Joaquim de Lima e Ana Maria de Jesus, de Vairão, de 16/03/1858). (citado por ALVES, 1994, p. 90).

Assim, na tentativa de obedecer, pelo menos em parte, à legislação que previa, desde 1867, a partilha igualitária na questão da herança, os gastos feitos pela família para viabilizar a viagem e a formação prévia necessária daqueles que não herdariam a propriedade familiar eram devidamente contabilizados e referidos como pagamento da "legítima" nos testamentos e inventários. Além disso, o documento expõe o interesse dos pais em investir na emigração como solução para que os filhos alcançassem sucesso econômico e profissional, mesmo após a ocorrência de tentativas anteriores frustradas.

Enfim, a análise relativa aos emigrantes mais jovens mostrou que este grupo era composto, prioritariamente, por indivíduos que, devido à preparação técnica ou alfabética, podiam se dedicar às atividades comerciais ou ofícios, tendo maiores chances de sucesso econômico e profissional. Eram estes jovens que, após alguns anos, promoviam ou facilitavam a vinda de familiares ou conhecidos, integrando-os nas atividades laborais, principalmente no comércio e na pequena indústria (ALVES, 1994, p. 9).

\section{Considerações finais}

Como a maioria dos imigrantes que retornaram a Portugal, pouco tempo depois de terem chegado ao Paraná, Francisco Fernandes, nosso personagem, não deixou memórias de sua experiência, aparentemente marcada pelo fracasso. Mesmo assim, a partir das conexões feitas entre documentos de natureza diversa, foi possível tirá-lo do anonimato e conhecer um pouco mais sobre a sua trajetória. Um simples registro, feito em ata pelo diligente secretário da Sociedade Portuguesa, identificando-o como imigrante por- 
tuguês, acabou sendo a chave que possibilitou o rastreamento de sua identidade junto aos registros de passaporte disponíveis nos arquivos distritais portugueses, permitindo a obtenção de informações sobre o lugar de onde ele vinha, idade, estado civil, ocupação, o ano em que saiu de Portugal, o local para onde desejava ir e o seu nível de instrução.

Assim como Francisco, muitos outros imigrantes que reimigraram para o território paranaense, durante a segunda metade do século XIX, somente puderam ser identificados graças ao cruzamento de fontes existentes em locais diversos. Fontes essas que, não raro, pouco tinham a dizer quando analisadas isoladamente. No entanto, ao serem cotejadas em conjunto com outros documentos, muitas vezes se transformaram no fio de Ariadne, permitindo o acesso às trajetórias individuais e coletivas de sujeitos históricos, cujas experiências estavam destinadas a permanecer no anonimato pelo fato de se distanciarem do modelo mais comum de deslocamento transnacional, ou seja, aquele em que o porto de desembarque era coincidente com o local de destino.

Tendo em vista a peculiaridade do grupo, e seguindo os ensinamentos do filósofo Walter Benjamin, procuramos nos aproximar do passado, "escavando" cuidadosamente a documentação, em busca de fragmentos que pudessem fornecer pistas a respeito de imigrantes que, bem ou mal sucedidos, buscaram o Paraná como um novo porto de chegada.

Sob este enfoque e, acima de tudo, acreditando que, a partir das trajetórias de vida e da reconstrução histórica das experiências individuais e coletivas, é possível compreender comportamentos, pertencimentos, apropriações e sentimentos, identificamos, entre os milhares de nomes registrados nos livros de passaporte, quase uma centena e meia de imigrantes cujas escolhas foram definitivas para a sua inserção no contexto histórico da sociedade paranaense.

Vale lembrar que, se do ponto de vista quantitativo os imigrantes portugueses não podem ser equiparados a outros grupos étnicos com maior representatividade numérica no contexto paranaense da segunda metade do século XIX, eles desempenharam importante papel nas áreas econômica, social e cultural, merecendo por isso novas investigações que permitam ampliar os conhecimentos sobre o grupo. 


\section{Referências}

ALVES, Jorge Fernandes. Os brasileiros: emigração e retorno no Porto oitocentista. Porto: edição do autor, 1994.

(Coord.). Os brasileiros da emigração. Seminário no Museu Bernardino Machado. Câmara Municipal de Vila Nova de Famalicão. 22 a 23 de setembro de 1998. ANDREAZZA, Maria Luiza. O paraíso das delícias: um estudo da imigração ucraniana. Curitiba: Aos Quatro Ventos, 1999.

ARRUDA, José Jobson de Andrade. A expansão europeia oitocentista: emigração e colonização. População e Sociedade, v. 14, p. 13-40, 2007. Disponível em: <http:// www.cepese.pt/portal/investigacao/publicacoes/tt-populacao-e-sociedade/revista-populacao-e-sociedade-no-14>. Acesso em: 10/02/2011.

BENJAMIN, Walter. Rua de mão única. Rio de Janeiro, Brasiliense, 1987.

BHABHA, Homi K. O local da cultura. Belo Horizonte: UFMG, 1998.

BOSCHILIA, Roseli. A sociedade portuguesa em Curitiba: um projeto identitário (1878-1900). In: MATOS, Maria Izilda; SOUSA, Fernando de; HECKER, Alexandre. (Org.). Deslocamentos e histórias: os portugueses. Bauru: Edusc, 2008.

CAPELA, José Viriato; FERREIRA, Maria da Conceição Falcão. Saídas clandestinas do Norte de Portugal para o Brasil em meados do século XIX. In: ALVES, Jorge Fernandes (Coord.). Os "brasileiros" da emigração. Vila Nova de Famalicão: Câmara Municipal de Vila Nova de Famalicão, 1999.

CARDOSO, Milena W. José Fernandes Loureiro: um imigrante português em Curitiba - 1860-1908. Curitiba: UFPR, 2010.

FIAMONCINI, Celina. Imigração, cultura e identidade: portugueses e o comércio em Curitiba no final do século XIX. Monografia (Bacharelado em História) - Setor de Ciências Humanas, Letras e Artes, Universidade Federal do Paraná, Curitiba, 2008.

GENARO, Luana C. A inserção dos descendentes de imigrantes portugueses no campo intelectual de Curitiba (1912-1938). Curitiba: UFPR, 2011.

HOBSBAWM, Eric J. A era do capital: 1848-1875. Rio de Janeiro: Paz e Terra, 1996.

KERBAUY, Maria Teresa Miceli; TRUZZI, Oswaldo. Globalização, migrações internacionais e novos desafios à cidadania. Perspectivas, São Paulo, v. 31, p.123135, jan./jun. 2007.

GLICK-SCHILLER, Nina; BASCH, Linda; BLANC-SZANTON, Cristina. Towards a transnational perspective on migration. Annals of the New York Academy of Sci- 
ences. Nova York, v. 645, p.145-174, 1992.

LEITE, Joaquim Costa. A viagem. In: PORTUGAL, Comissão Nacional para as comemorações dos descobrimentos portugueses. Os brasileiros de torna-viagem no Noroeste de Portugal. Comissão Nacional para as comemorações dos Descobrimentos portugueses.Lisboa: Comissão Nacional para as comemorações dos Descobrimentos portugueses, 2000.

MARTINS, Oliveira. A emigração portuguesa, 1931. In: Fomento rural e emigração. Lisboa, 1956. p. 218-252.

PASSOS, Giseli Cristina dos. A presença dos imigrantes portugueses no Paraná na segunda metade do século XIX. Monografia (Curso de Licenciatura e Bacharelado em História) - Setor de Ciências Humanas, Letras e Artes, Universidade Federal do Paraná, Curitiba, 2009.

PEREIRA, Miriam Halpern. A política portuguesa de emigração (1850-1930). Bauru: Edusc; Portugal: Instituto Camões, 2002.

ROCHA-TRINDADE, Maria Beatriz; CAEIRO, Domingos. Portugal-Brasil. Migrações e migrantes (1850-1930). Lisboa: Edições INAPA, 2000.

RODRIGUES, Henrique. Emigração e emigrantes: Vale do Lima no século XIX. Viana do Castelo, 2006.

SANTOS, Eugênio dos. Os brasileiros de torna-viagem no Noroeste de Portugal. In: PORTUGAL, Comissão Nacional para as comemorações dos Descobrimentos portugueses. Os brasileiros de torna-viagem no Noroeste de Portugal. Comissão Nacional para as comemorações dos descobrimentos portugueses. Lisboa: Comissão Nacional para as comemorações dos descobrimentos portugueses, 2000.

\section{Fontes}

A REPÚBLICA. Curitiba, 1890-1900. Seção Anúncios.

BASE DE DADOS. A emigração do Norte de Portugal para o Brasil (1835-1973) [em linha]. Disponível em: <http://www.cepese.pt/portal/investigacao/bases-de-dados/emigracao/res_pesq titulares $>$. Acessado no período entre 20 de julho e 20 de dezembro de 2011.

BOLETIM INFORMATIVO DA CASA ROMÁRIO MARTINS. A Rua 15 e o comércio no início do século. Curitiba: Fundação Cultural de Curitiba, v. 23, n. 113, jul. 1996.

CARVALHO, Augusto. O Brazil, colonização e emigração. Typographia de Bartholomeu H. de Moraes, 1875. 
CORRESPONDÊNCIAS DO GOVERNO DO PARANÁ. 1855-1895. Curitiba: Arquivo Público do Paraná.

DEZENOVE DE DEZEMBRO. Curitiba. 1885-1890. Seção Anúncios.

LIVROS DE REGISTROS DE DESEMBARQUE DE IMIGRANTES NO PORTO DE PARANAGUÁ. 1876-1879 E 1885-1896. Curitiba: Arquivo Público do Paraná.

RELATÓRIO do Presidente Adolpho Lamenha Lins, apresentado a Assembleia Legislativa do Paraná, em 15 de fevereiro de 1876. Curitiba, 1876.

RELATÓRIO do Presidente Francisco Liberato de Mattos, apresentado na abertura da Assembleia Legislativa Provincial, em 7 de janeiro de 1858. Curitiba, Tipografia Paranaense, 1858.

RELATÓRIO do Presidente Luiz Alves L. de Oliveira, apresentado na abertura da Assembleia Legislativa Provincial, em 22 de agosto de 1884. Curitiba, Tipografia Paranaense, 1884.

SOCIEDADE BENEFICENTE PORTUGUESA PRIMEIRO DE DEZEMBRO. Livro de Associados. Curitiba, 1878-1898. Secretaria da Sociedade Portuguesa Primeiro de Dezembro.

Recebido em fevereiro de 2012.

Aprovado em março de 2012. 